\title{
Intelligent Detection Platform for Simultaneous Detection of Multiple MiRNAs Based on Smartphone
}

Yu Tian",\#, Lili Zhang, \#, Hanjie Wanga, *, Wanying Jia, Ziyu Zhangd, Yingying Zhanga, Zhengchun Yang ${ }^{\mathrm{c}}$, Zongsheng $\mathrm{Cao}^{\mathrm{c}}$, Shufang Zhang ${ }^{\mathrm{b}}$, Jin Chang, *

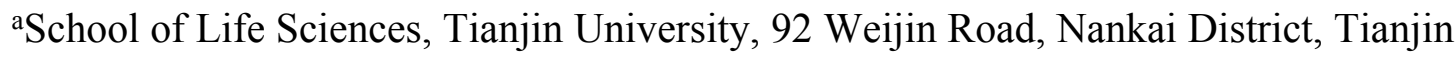
300072, China

bSchool of Electrical and Information Engineering, Tianjin University, 92 Weijin Road, Nankai District, Tianjin 300072, China.

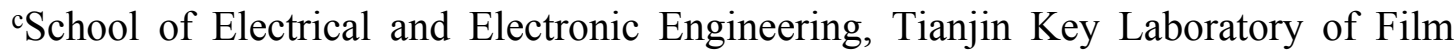
Electronic \& Communication Devices, Tianjin University of Technology, Tianjin 300384, China.

dTianjin International Engineering Institute, Tianjin University,92 Weijin Road, Nankai District, Tianjin 300072, China.

Address correspondence to E-mail: wanghj@tju.edu.cn andjinchang@tju.edu.cn

\#These authors contributed equally to this work. 
Table S1. Nucleic acid sequences.

\begin{tabular}{cr}
\hline $\begin{array}{c}\text { miR-21 } \\
\text { probe }\end{array}$ & 5 Acryd/GAT ATA TTT TAT CAA CAT CAG TCT GAT AAG CTA/3InvdT \\
\hline $\begin{array}{c}\text { let-7a } \\
\text { probe } \\
\text { miR-21 } \\
\text { target } \\
\text { let-7a } \\
\text { target } \\
\begin{array}{c}\text { Biotinylated } \\
\text { linker }\end{array}\end{array}$ & 5 Acryd/GAT ATA TTT TAA ACT ATA CAA CCT ACT ACC TCA/3InvdT \\
\hline
\end{tabular}


Table S2. hydrogel precursor prepolymer compositions

\begin{tabular}{cc}
\hline Polyethylene Glycol Diacrylate (PEG-DA-700) & $20 \%$ \\
\hline Polyethylene Glycol (PEG 200) & $40 \%$ \\
Darocur & $5 \%$ \\
$3 \times$ Tris-EDTA Buffer (3× TE) & $35 \%$ \\
\hline
\end{tabular}


Table S3. Ligation buffer compositions. The buffer for the ligation portion of the labeling steps consisted of the elements in table added to $1 \times \mathrm{TE}$ buffer.

\begin{tabular}{ll}
\hline Buffer component & Amount (1 mL) \\
\hline TET & $900 \mu \mathrm{L}$ \\
$\mathrm{NaCl}$ & $0.0031 \mathrm{~g}$ \\
$\mathrm{NEBuffer} 2$ (New England Biolabs) & $100 \mu \mathrm{L}$ \\
ATP (New England Biolabs) & $2 \mu \mathrm{L}$ \\
A12 universal linker (New England Biolabs) & $0.33 \mu \mathrm{L}$ \\
T4 DNA ligase & $1.88 \mu \mathrm{L}$ \\
\hline
\end{tabular}


Table S4. Recoveries of miR-21 and let-7a from human serum

\begin{tabular}{cccccc}
\hline \multirow{2}{*}{ Samples } & Analytes & $\begin{array}{c}\text { Added } \\
(\mathrm{fmol})\end{array}$ & $\begin{array}{c}\text { Founded } \\
(\mathrm{fmol})\end{array}$ & $\begin{array}{c}\text { Recovery } \\
(\%)\end{array}$ & RSD (\%) \\
\hline \multirow{2}{*}{1} & miR-21 & $10^{2}$ & 96.33 & 96.33 & 2.1 \\
& let-7a & $10^{2}$ & 98.67 & 98.67 & 8.6 \\
\multirow{2}{*}{2} & miR-21 & $10^{3}$ & 926.67 & 92.67 & 4.1 \\
& let-7a & $10^{3}$ & 1256.33 & 125.63 & 9.2 \\
& miR-21 & $10^{5}$ & 88705.00 & 88.71 & 7.4 \\
\hline
\end{tabular}



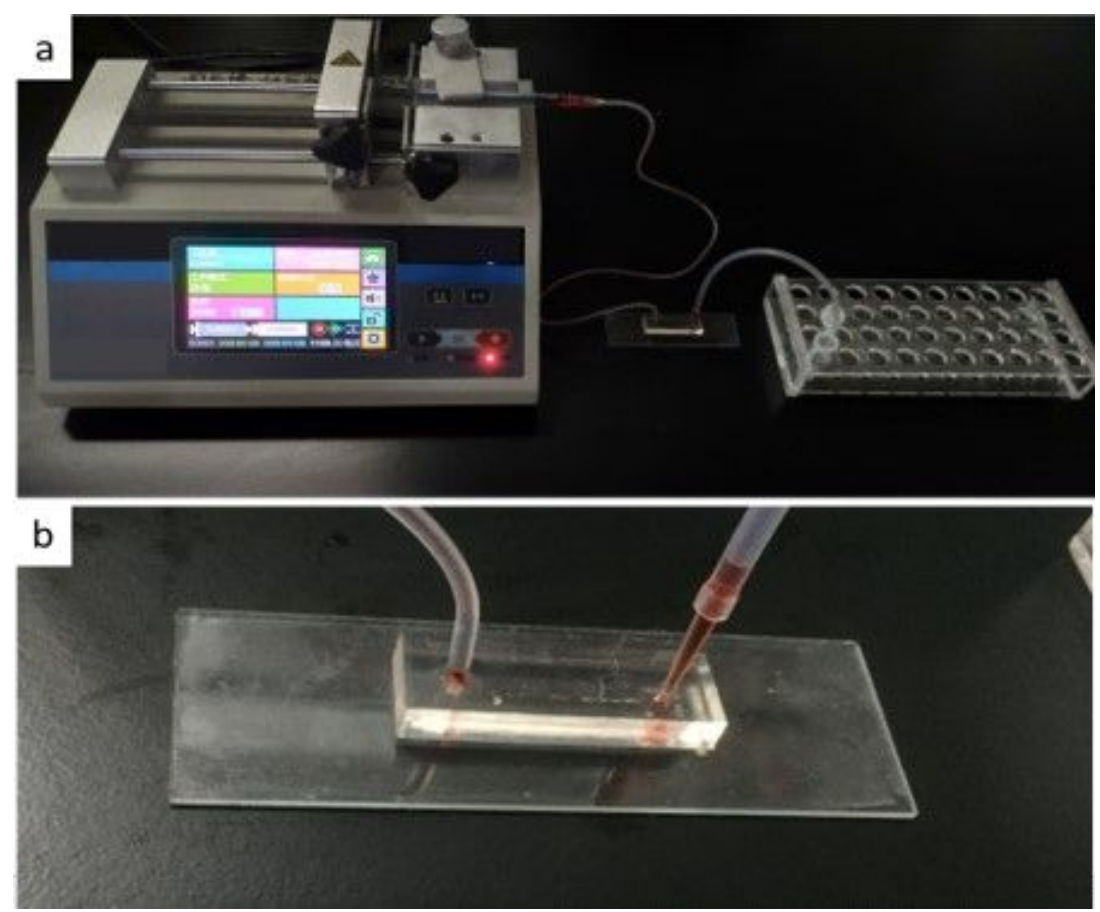

Figure S1. (a)Sample flow diagram in microfluidic platform. (b) Sample display of microfluidic chip 


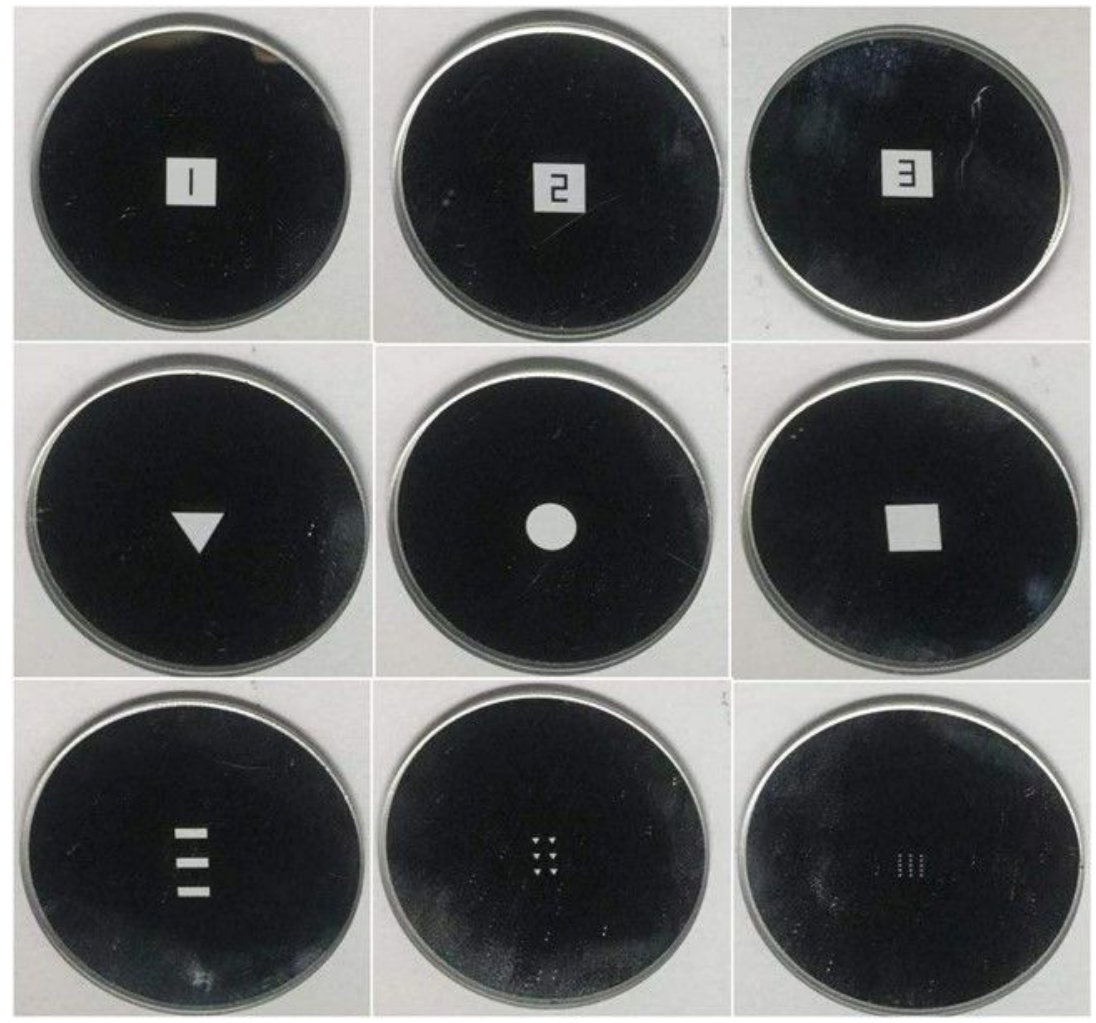

Figure S2. Different shapes of photomasks. 

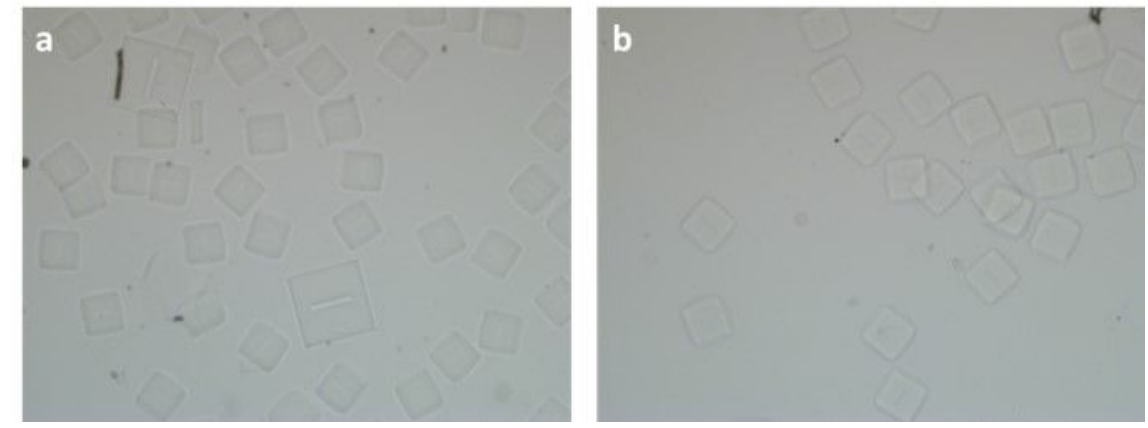

Figure S3. (a) Particles stored at room temperature for one month. (b) Particles stored at $4^{\circ} \mathrm{C}$ for one month. 


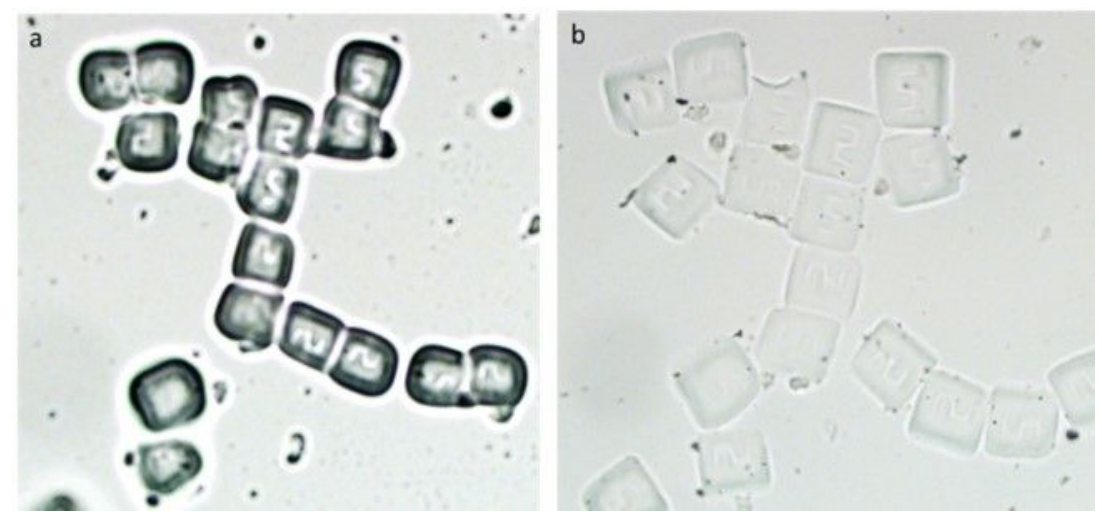

Figure S4. (a) Image of hydrogel particles after drying. (b) Appearance of hydrogel particles after adding water. 


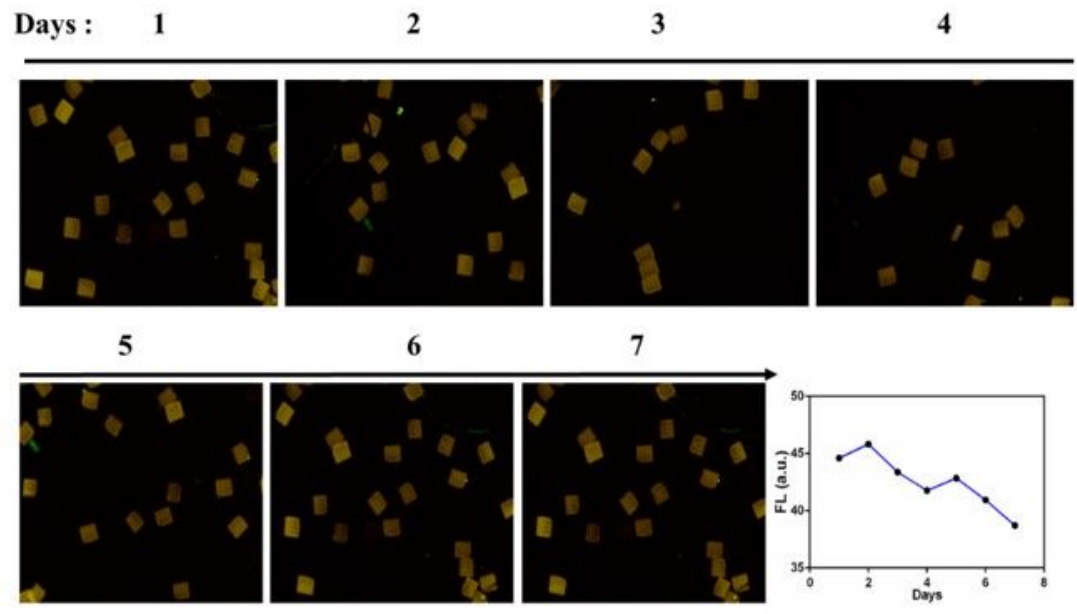

Figure S5. Fluorescence stability test of the reaction product in one week $\left(4^{\circ} \mathrm{C}\right.$, Dark $)$. 


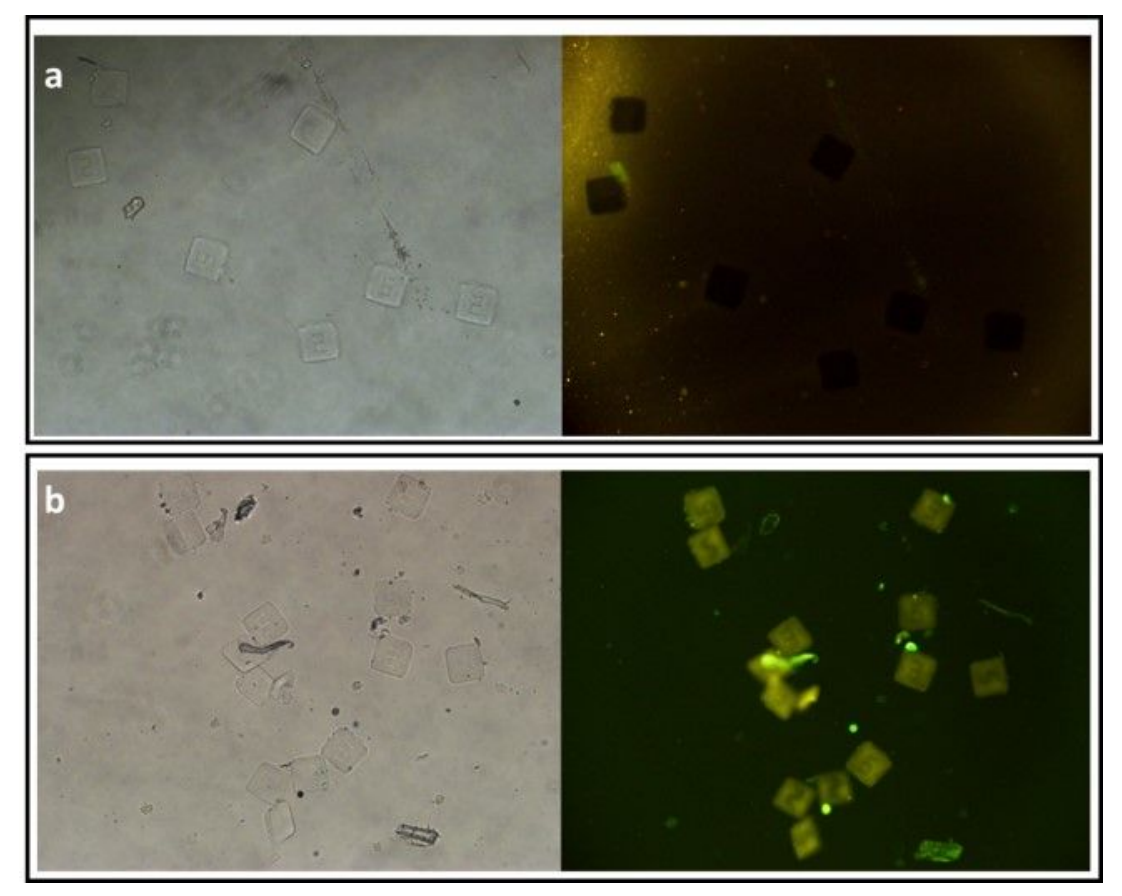

Figure S6. (a) Particle fluorescence after no target miRNA detection reaction. (b) Particle fluorescence after add target miRNA detection reaction

Movies.

Movie 1 - Hydrogel particle automated synthesis process

Movie 2 - Hydrogel particle recovery shape process 